\title{
Lung Volume and Lung Mechanics in Infancy Lateral or Supine Posture?
}

\author{
P. HELMS, ${ }^{(3.3)}$ M. G. HULSE, AND D. J. HATCH
}

The Respiratory Laboratory, Hospital for Sick Children, Great Ormond Street, London WCIN 3JH, United Kingdom

\begin{abstract}
Summary
In 23 infants and young children aged from 3 wk to $2 \frac{1}{2}$ years, lung volume, by plethysmography, dynamic lung compliance and total pulmonary resistance with air-filled balloons and pneumotachography, have been measured in the supine and right lateral postures in order to observe any possible systematic differences in either body position. Fourteen subjects were studied under light sedation, the remaining nine under general anaesthesia before elective surgery. In the sedated group, no significant differences were found between the two positions for lung mechanics. In the anaesthetised group the only measurement that varied with position was dynamic lung compliance, being lower in the supine posture $(P<0.05)$. In one of the sedated infants with predominantly left sided lung disease, large position dependent changes in lung volume and lung mechanics were observed suggesting that care should be taken in interpreting lung function tests in infants with unilateral lung disease. In the anaesthetised subjects, the finding of reduced ratios of esophageal to mouth pressure change during brief airway occlusions, suggests that under these conditions pleural pressure changes were unequally distributed.
\end{abstract}

Normal values for lung volume have been established in infancy and early childhood. Measurements can be made by whole body plethysmography $(2,7,13,21,24,26,28)$, (Thoracic Gas Volume, T.G.V.) or by gas dilution $(6,30)$. (Functional Residual Capacity, F.R.C.).

In the child below the age of 2 years, all studies have been performed in the supine posture during quiet sleep. The importance of ensuring this phase of sleep has been demonstrated by Henderson-Smart and Read (15) who found significant falls in T.G.V. during active sleep in normal fullterm infants. Normal ranges for lung mechanics have also been reported in the same young age group and most of these studies have been performed in the supine posture $(16,24,25,26,28)$.

Studies in normal adult subjects have shown falls in F.R.C. from the erect to the supine posture, proportional to the stature of the individual (1), but with smaller changes between the supine to lateral or prone position $(1,19)$. Differences in calculated values of lung compliance between the erect and supine position have been interpreted as being due to mediastinal compression of the intraesophageal air-filled balloon $(9,20)$ and has lead to the suggestion that measurements of lung mechanics in infants and young children should be made in the right lateral position. (28).

The purpose of this study was to measure any differences between lung volume and lung mechanics in the right lateral and supine positions and if any differences were observed, to decide which was the most appropriate body posture in which these measurements should be made.

\section{MATERIALS AND METHODS}

End-expiratory lung volume was measured by brief airway occlusions within a constant volume whole body plethysmograph
(13) and lung mechanics during tidal airflow through a heated screen pneumotachograph (29). Intraesophageal pressure changes $(\Delta \mathrm{Pes})$ were measured with catheter mounted air-filled balloons containing the smallest volume of air $(0.1-0.3 \mathrm{ml})$ to bring them into their range of infinite compliance. Full details of the type of balloons and the transducers used are described elsewhere (3) so only a brief description is given here. All transducers, together with their attached tubing, had flat amplitude: frequency responses with no detectable phase differences up to 10 Hertz. Volume displacement coefficient of the esophageal pressure recording system was $0.003 \mathrm{ml} \mathrm{cm} \mathrm{H} 0_{2} 0^{-1}$. The plethysmograph had a flat amplitude: frequency response up to $9 \mathrm{Hertz}$. All signals were recorded into light-sensitive paper with an ultraviolet light oscillograph and all calculations made from the time base recordings, each result shown being the mean of 5-10 estimations.

Twenty-three subjects, some with normal lungs and others with a variety of cardiorespiratory diseases, were studied (Table 1). Ages ranged from 3 wk to $2 \frac{1}{2}$ years. Nine subjects were studied under general anaesthesia before elective surgery, the remaining 14 after $1 \mathrm{~h}$ sedation with chloral hydrate $\left(50-100 \mathrm{mg} \cdot \mathrm{kg}^{-1}\right)$. Measurements were performed in the supine and right lateral posture in random order during quiet sleep (4). In order to detect any change in the ability of the esophageal balloon to record the surrounding pressure changes, brief airway occlusions were performed, when tolerated, in both body positions. It has been previously shown in normal infants and infants recovering from cardiorespiratory disease that the resulting ratio of change in intraesophageal pressure to change in mouth pressure $\Delta \mathrm{Pes} / \Delta \mathrm{Pm}$ can be used to detect balloon malfunction (3). Any compressive effect of the mediastinal contents in the supine position was also assessed by comparing end-expiratory intraesophageal pressures recorded from the balloons in the lateral and supine positions. Informed parental consent was obtained for these studies and the approval of the Hospital Ethical Committee obtained.

\section{RESULTS}

There was little difference between the mean data obtained in each position for either sedated or anaesthetised groups (Tables 2 and 3). No significant differences for either C. Dyn or T.P.R. were found in the sedated group. Only three individuals in this group had T.G.V. measured in both positions and one of these (J.R.) had a large $(35 \%)$ fall in T.G.V. from the supine to lateral position from $130 \mathrm{ml}$ supine to $96 \mathrm{ml}$ right lateral. He also had a fall in $\mathrm{C}$. Dyn from $7.5 \mathrm{ml} \cdot \mathrm{cm} \mathrm{H}_{2} \mathrm{O}^{-1}$ to $4.6 \mathrm{ml} \cdot \mathrm{cm} \mathrm{H}_{2} \mathrm{O}^{-1}$ and a rise in T.P.R. from $27 \mathrm{~cm} \mathrm{H} \mathrm{H}_{2} 0 \cdot$ liter ${ }^{-1} \cdot \mathrm{sec}^{-1}$ to $41 \mathrm{~cm} \mathrm{H}_{2} 0 \cdot$ liter $^{-1} \cdot \mathrm{sec}^{-1}$. When the changes in lung mechanics from the supine to lateral posture were expressed as \% predicted of the normal values expected from the lung volume at which they were measured (28), the changes were found to be broadly consistent with the change in T.G.V: C. Dyn changing from 90 to $84 \%$ predicted and T.P.R. from 105 to $130 \%$ predicted.

In the anaesthetised group, C. Dyn was found to vary significantly with body position, being reduced in the supine compared 
Table 1. Clinical details and lung function results of subjects studied ${ }^{1}$

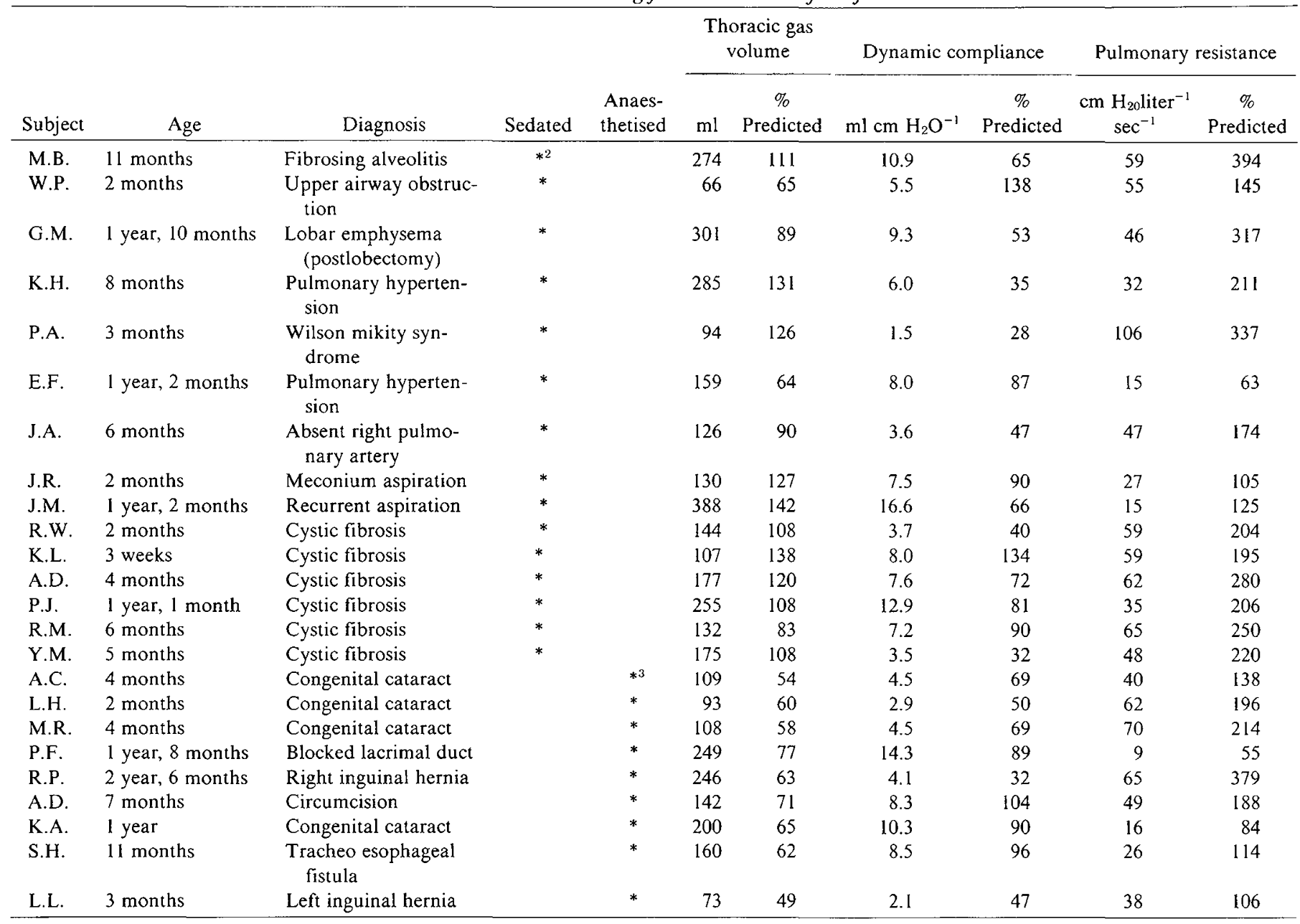

' Lung function tests are expressed in \% predicted according to normal data of J. Stocks (28). Thoracic gas volume predicted on body length (2 S.D. range 80-120\%). Compliance on T.G.V. (2 S.D. range 60-140\%). Resistance on thoracic gas volume (2 S.D. range 70-200\%).

${ }^{2}$ Asterisk refers to those infants who were sedated.

${ }^{3}$ Asterisk refers to those infants who were anaesthetised.

Table 2. Effect of body position in sedated infants

\begin{tabular}{|c|c|c|c|c|c|c|}
\hline & \multicolumn{2}{|c|}{ Lateral } & \multicolumn{2}{|c|}{ Supine } & \multirow[b]{2}{*}{$\mathrm{N}$} & \multirow{2}{*}{$\begin{array}{c}\text { Comparisons } \\
\mathrm{P} \text { value }\end{array}$} \\
\hline & Mean & S.D. & Mean & S.D. & & \\
\hline $\begin{array}{r}\text { Respiratory rate } \\
\text { (breaths/min) }\end{array}$ & 45 & 18 & 49 & 20 & 15 & N.S. \\
\hline Tidal volume $(\mathrm{ml})$ & 52.5 & 28.5 & 48.3 & 25.8 & 15 & N.S. \\
\hline $\begin{array}{l}\text { Compliance (ml/ } \\
\left.\mathrm{cm} \mathrm{H}_{2} \mathrm{O}\right)\end{array}$ & 7.4 & 4.2 & 7.5 & 3.9 & 15 & N.S. \\
\hline $\begin{array}{l}\text { Pulmonary resist- } \\
\text { ance }\left(\mathrm{cm} \mathrm{H}_{2} \mathrm{O} /\right. \\
\text { liter } / \mathrm{sec})\end{array}$ & 51.2 & 24.5 & 45.8 & 24.9 & 15 & N.S. \\
\hline $\begin{array}{l}\Delta \mathrm{Pes} / \Delta \mathrm{Pm} \text { during } \\
\text { occlusion }\end{array}$ & 0.97 & 0.16 & 0.99 & 0.13 & 9 & N.S. \\
\hline $\begin{array}{l}\text { Thoracic gas vol- } \\
\text { ume }^{1}(\mathrm{ml})\end{array}$ & 14 & $\begin{array}{l}6 \\
1 \\
0\end{array}$ & $\begin{array}{l}13 \\
13 \\
2 .\end{array}$ & & 3 & \\
\hline
\end{tabular}

${ }^{1}$ Thoracic Gas Volume was measured in both positions in three subjects, hence the individual values are given in the table.

${ }^{2} P$ values derived from paired $t$ tests.

with the lateral posture $(P<0.05)$ whereas T.P.R. remained unchanged. No signficant changes were observed in the $\Delta \mathrm{Pes} /$ $\Delta \mathrm{Pm}$ ratio during airway occlusion in either group and in the anaesthetised group no significant changes in T.G.V. were ob-
Table 3. Effect of body position in anaesthetised infants

\begin{tabular}{|c|c|c|c|c|c|c|}
\hline & \multicolumn{2}{|c|}{ Lateral } & \multicolumn{2}{|c|}{ Supine } & \multirow[b]{2}{*}{$\mathrm{N}$} & \multirow{2}{*}{$\begin{array}{c}\text { Comparisons } \\
P \text { value }^{1}\end{array}$} \\
\hline & Mean & S.D. & Mean & S.D. & & \\
\hline $\begin{array}{l}\text { Respiratory rate } \\
\text { (breaths/min) }\end{array}$ & 48 & 13 & 52 & 17 & 9 & N.S. \\
\hline Tidal volume (ml) & 40.6 & 20.7 & 39.3 & 19.9 & 9 & N.S. \\
\hline $\begin{array}{l}\text { Compliance (ml/ } \\
\left.\mathrm{cm} \mathrm{H}_{2} \mathrm{O}\right)\end{array}$ & 7.6 & 4.4 & 6.6 & 4.0 & 9 & $<0.05$ \\
\hline $\begin{array}{l}\text { Pulmonary resist- } \\
\text { ance }\left(\mathrm{cm} \mathrm{H}_{2} \mathrm{O} /\right. \\
\text { liter } / \mathrm{sec})\end{array}$ & 43.1 & 17.2 & 41.5 & 21.6 & 9 & N.S. \\
\hline $\begin{array}{l}\Delta \mathrm{Pes} / \Delta \mathrm{Pm} \text { during } \\
\text { occlusion }\end{array}$ & 0.85 & 0.07 & 0.80 & 0.08 & 8 & N.S. \\
\hline $\begin{array}{l}\text { Thoracic gas vol- } \\
\text { ume (ml) }\end{array}$ & 139.3 & 49.5 & 142.2 & 54.7 & 9 & N.S. \\
\hline
\end{tabular}

${ }^{1} P$ values derived from paired $t$ tests.

served. The occlusion $\Delta \mathrm{Pes} / \Delta \mathrm{Pm}$ ratios were lower in the anaesthetised than in the sedated group in spite of using an identical balloon technique. Absolute intraesophageal pressures at endexpiration were higher in the supine than lateral position in all infants except one, the difference being significantly greater in the anaesthetised group (Fig. 1). 


\section{DISCUSSION}

This data indicate that in sedated infants there is no significant difference in C. Dyn or T.P.R. obtained in either right lateral or supine positions and is in agreement with similar studies in newborns (18). In anaesthetised infants and young children, supine C. Dyn may be lower than in the lateral posture. Lung volume is reduced by general anaesthesia in this age group (17) and the

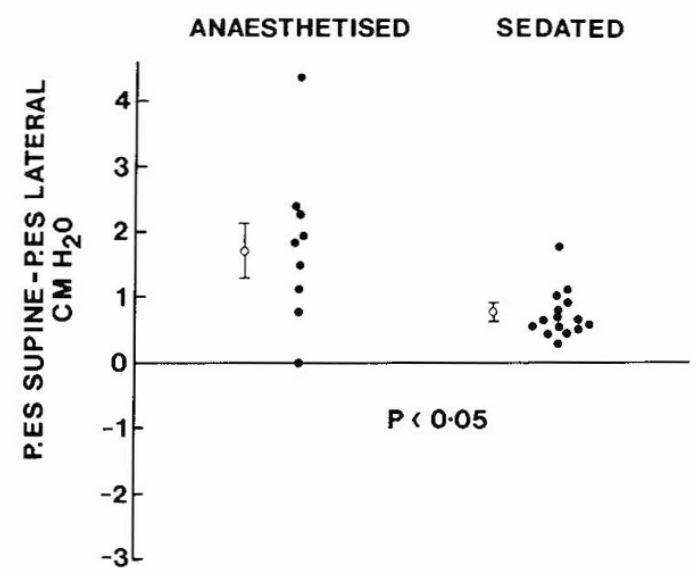

Fig. 1. Differences between end tidal intraesophageal pressure between the supine and right lateral postures in nine anaesthetised infants and 15 sedated infants. Mean values are shown with the open symbols together with S.E. The significance (unpaired $t$ test) of these differences between the two groups is also shown. reduced lung compliance is possibly related to a greater effect of the mediastinal contents at this lower lung volume. The greater increase in end-tidal intraesophageal pressure from the lateral to supine position in this group, compared with the sedated infants, (Fig. 1) supports this conclusion. These effects should be taken into account before drawing conclusions from studies in anaesthetised children.

The fact that positional changes in the measurement of static lung compliance in several early studies in adult subjects $(9,20)$ were not confirmed in subsequent studies $(11,23)$ can be explained by variations in esophageal balloon technique. In the earlier studies $(9,20)$ balloons containing $1.0-2.0 \mathrm{ml}$ air were used whereas in the later studies volumes of approximately $0.2 \mathrm{ml}$ were used $(11,23)$, similar to the volumes used here. Interference of the esophageal pressure signal due to cardiac pulsation also increases with larger balloon volumes (3).

The occlusion $\Delta \mathrm{Pes} / \Delta \mathrm{Pm}$ ratio has been found to be close to unity in normal sedated infants when esophageal balloons of the ideal type are used in their infinite complaint range (3). This is confirmed in the sedated infants studied here (Table 2). In the anaesthetised group however, the $\Delta \mathrm{Pes} / \Delta \mathrm{Pm}$ ratios were considerably reduced in spite of an identical balloon technique (Table 3 ). This challenges the assumption that changes in intraesophageal pressure invariably reflect mean pleural pressure changes. If, in these anaesthetised subjects, the esophageal balloons accurately record the pressure changes around them, then it would appear that in these subjects pleural pressure changes were not equally distributed and areas of larger pleural pressure change must have been occurring at some distance from the balloon. Unequal distribution of pleural pressure has been demonstrated in anaesthetised supine dogs (8), and more recently when segmental airway
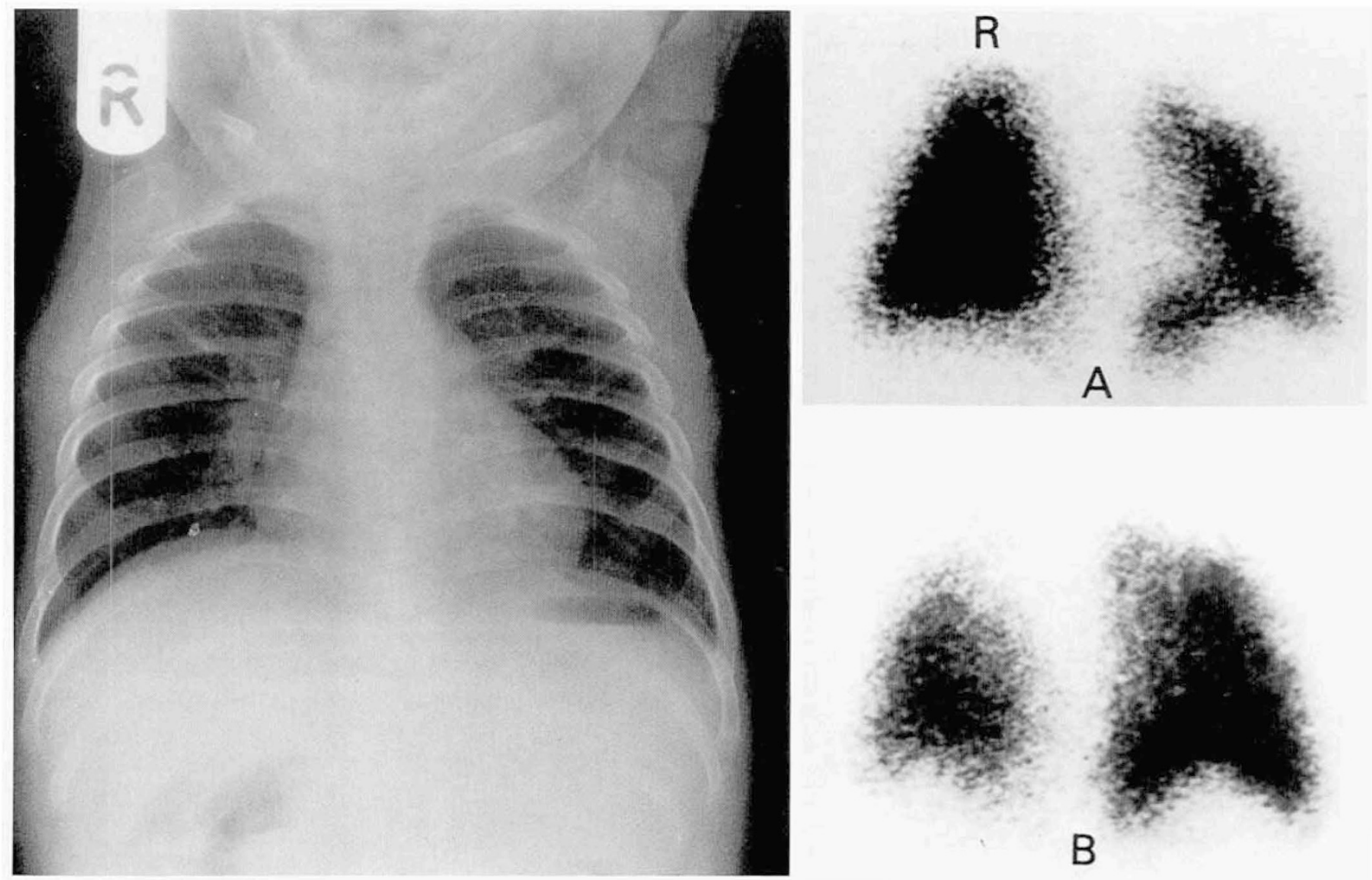

Fig. 2. Anteroposterior chest radiograph and posterior $\mathrm{Kr} 8 \mathrm{~lm}$ ventilation scans in a 2-month-old infant (J.R.) recovering from meconium aspiration. The lung scan in the supine posture (A) shows an even distribution of inhaled radionuclide in the right lung with a defect in the midzone of the left lung. The right lateral scan (B) shows a marked redistribution of the inhaled radionuclide away from the dependent lung with an apparent reduction in the size of the ventilated dependent lung. 


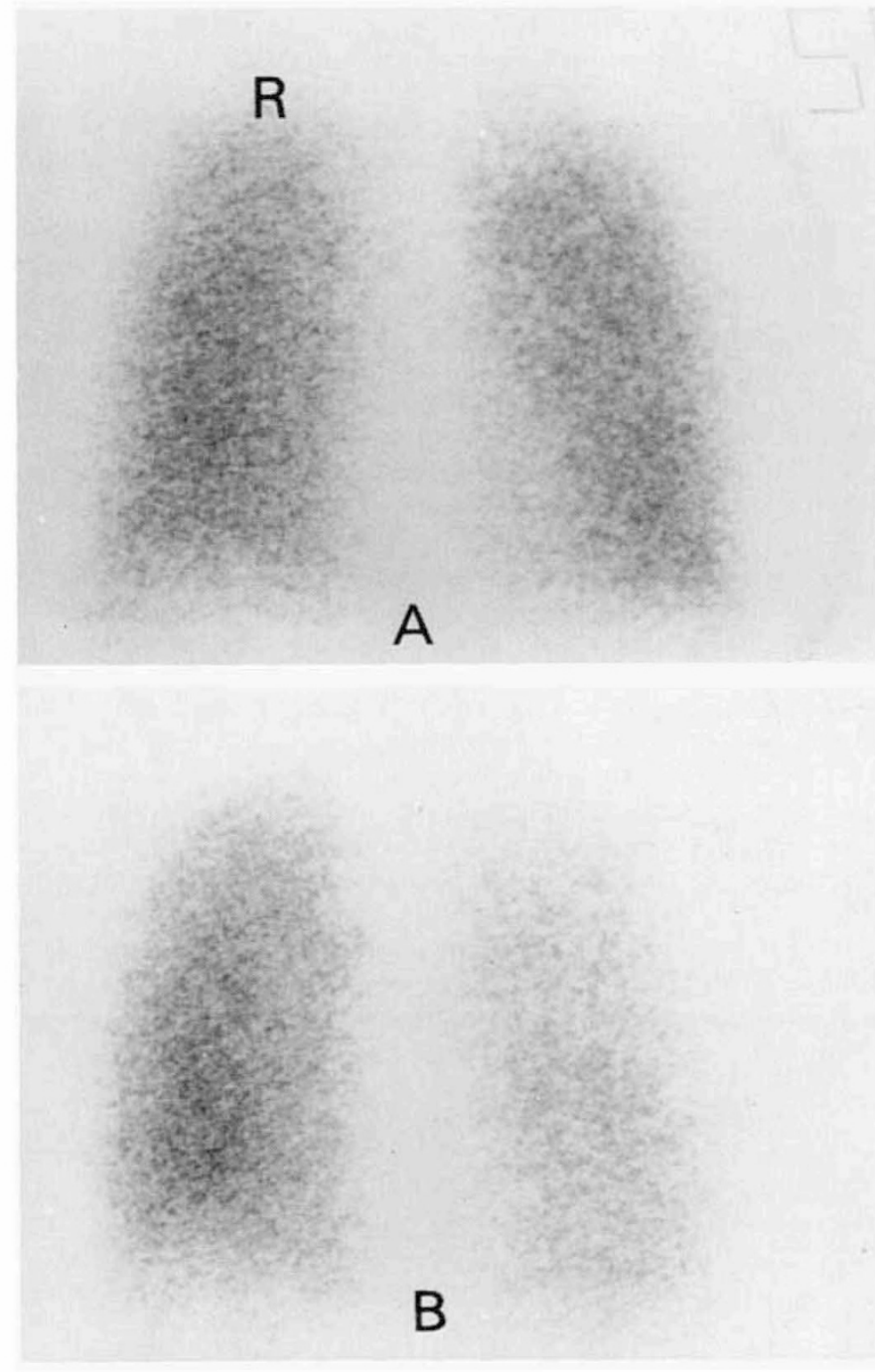

Fig. 3. Posterior $\mathrm{Kr} 81 \mathrm{~m}$ ventilation lung scans in a 33-year-old adult subject (P.J.H.) with normal lung function. The supine scan (A) shows an even distribution of the inhaled radionuclide to both lungs. The right lateral decubitus scan shows a redistribution of the inhaled radionuclide to the dependent lung. The size of the ventilated dependent lung is well preserved.

closure has been produced experimentally (5). These observations are of interest to those investigators wishing to understand the mechanical behaviour of the lungs in infancy and early childhood and challenge the assumption that esophageal pressure changes invariably reflect mean pleural pressure changes. They do not detract from the conclusions already drawn, namely that the mediastinal contents have insignificant effects on the ability of intraesophageal balloons to record local pleural pressure changes, provided that ideal balloons containing small air volumes are used.

The sedated subject J.R. in whom lung volume was markedly reduced in the right lateral posture, with subsequent changes in C. Dyn and T.P.R., also had radionuclide lung scanning with Technetium $99 \mathrm{~m}$ microspheres and Krypton $81 \mathrm{~m}$ gas $(\mathrm{Kr} 81 \mathrm{~m})$ performed as part of his clinical assessment (12). In an attempt to understand how lung volume could fall in the lateral posture, posterior $\mathrm{Kr} 8 \mathrm{~lm}$ ventilation scans were repeated in the supine and right lateral positions. This demonstrated a marked reduction in the ventilation of the dependent lung (Fig. 2).

At first sight, this observation would appear to be in conflict with work on the regional distribution of ventilation in adult subjects in whom dependent lung regions are preferentially ventilated and perfused (19,31), (Fig. 3); however, the highly compliant chest wall of the infant $(10,27)$ results in a low distending pressure around the lung (14), which in turn allows the lung to recoil to a relatively lower position on its pressure/volume history than found in the relaxed young adult. At this low lung volume, gravity dependent airway closure (22) is more likely to occur, with the result that a larger proportion of the total ventilation is distributed to the upper lung (19). The fall in lung volume in the right lateral position in infant J.R. is related to these observations on the effects of gravity on the lungs. Studies in adult subjects in the lateral posture and close to residual volume have shown that the dependent lung becomes considerably smaller than the upper lung (19). If the upper lung has been shown in the supine or erect position, when the effects of gravity are equal on both lungs, to have a limited volume excursion it is possible to understand how that same lung would fail to distend in response to a gravitational pressure gradient. If the dependent lung becomes smaller and the upper lung is unable to distend as it should, a fall in overall lung volume will occur.

In infants and young children with predominantly unilateral lung disease it can therefore be argued that the supine posture is the most suitable in which to measure lung volume and lung mechanics. In most other infants both the supine and lateral postures are equally suitable. Data gathered in one posture would in most situations be comparable to that gained in the other.

In young anesthetised subjects the changes in lung compliance with body posture in the absence of lung volume change should be taken into account as should be possible effects of an unequal distribution of lung disease on overall lung volume with its subsequent effects on C. Dyn and T.P.R. The finding of reduced $\Delta \mathrm{Pes} / \Delta \mathrm{Pm}$ occlusion ratios in the anaesthetised subjects while using an improved esophageal technique (3) suggests that under these conditions and in this age group pleural pressure changes were not equally distributed.

\section{REFERENCES AND NOTES}

1. Agostoni. E. and Mead. J.: Statics of the respiratory system. In: Handbook of Physiology. Section 3. Respiration Vol. I. p. 398. (American Physiological Society. Washington D.C. 1964).

2. Auld, P.. Nelson, N. M., Cherry, R. B., Rudolph, A. J., and Smith. C. A. Measurement of thoracic gas volume in the newborn infant. J. Clin. Invest., 42: 476 (1963).

3. Beardsmore, C. S., Helms, P., Stocks, J.. Hatch, D. J., and Silverman, M. Improved esophageal balloon technique for use in infants. J. Appl. Physiol. Respir. Environ. Exercise. Physiol.. 49: 735 (1980).

4. Brazelton, T. B.: Neonatal behavioural assessment scale. In: Ed. Brazelton T.B. Clinics in Developmental Medicine. 50. p. 5. (Spastics International Medical Publications. William Heinemann Medical Books. London. 1973).

5. Brown, R.. Scharf. S.. and Ingram. R. H. Nonhomogeneous alveolar pressure swings in the presence of airway closure. J. Appl. Physiol. Respir. Environ. Exercise. Physiol., 49: 398 (1980)

6. Buist, A. S., Adams, B. E., Sexton, G. J., and Azzam, A. H.: Reference values for functional residual capacity and maximal expiratory flow in young children. Am. Rev. Respir. Dis., 122: 983 (1980).

7. Doershuk, C. F., Downs, T. D., Matthews, L. W., and Lough, M.D.: A method for ventilatory measurements in subjects 1 month to 5 years of age: normal results and observations in disease. Pediatr. Res., 4: 165 (1970).

8. Farhi, L., Otis. A. B., and Proctor, D. F.: Measurement of intrapleural pressure at different points in the chest of the dog. J. Appl. Physiol., 10: 15 (1957).

9. Ferris, B. G., Mead, J., and Frank. R. N.: Effect of body position on esophageal pressure and measurement of pulmonary compliance. J. Appl. Physiol., 14: 521 (1959).

10. Gerhardt, T. and Bancalari, E.: Chest wall compliance in full-term and premature infants. Acta. Pediatr. Scand., 69: 359 (1980).

11. Gillespie, D. J., Lai, Y. L., and Hyatt, R. E.: Comparison of esophageal and pleural pressures in the anaesthetised dog. J. Appl. Physiol.. 35: 709 (1973).

12. Gordon, I.. Helms, P., and Fazio, F.: Clinical applications of radio-nuclide lung scanning in infants and children. Brit. J. Radiol.. 54: 576 (1981).

13. Hatch, D. J. and Taylor, B. W.: Thoracic gas volume in early childhood. Arch. Dis. Child., 51: 859 (1976).

14. Helms. P., Beardsmore, C. S., and Stocks, J.: Absolute intraesophageal pressure at functional residual capacity in infancy. J. Appl. Physiol: Respir. Environ. Exercise. Physiol.. 51: 270 (1981).

15. Henderson-Smart, D. J. and Read, D. J. C.: Reduced lung volume during behavioural active sleep in the newborn. J. Appl. Physiol. Respir. Environ. Exercise. Physiol. 46: 1081 (1979).

16. Howlett, G.: Lung mechanics in normal infants and infants with congenital heart disease. Arch. Dis. Child., 47: 707 (1972).

17. Hulse. M. G., Helms, P., and Hatch, D. J.: Unpublished data.

18. Hutchinson, A. A., Ross, K. R., and Russell, G.: The effect of posture on ventilation and lung mechanics in pre-term and light-for-dates infants. Pediatrics, 64: 429 (1979). 
19. Kaneko, K., Milic-Emili, J., Dolovich, M. B., Dawson, A., and Bates, D. V Regional distribution of ventilation and perfusion as a function of body position. J. Appl. Physiol., 21: 767 (1966).

20. Knowles, J. H., Hong Suk, K. I., and Rahn, H.: Possible errors using esophageal balloon in determination of pressure-volume characteristics of the lung and thoracic cage. J. Appl. Physiol., 14: 525 (1959).

21. Krieger, I.: Thoracic gas volume in infancy. Amer. J. Dis. Child., 111: 393 (1966).

22. McCarthy, D. S., Spencer, R., Greene, R., and Milic-Emili, J.: Measurement of "Closing Volume" as a simple and sensitive test for early detection of small airway disease. Am. J. Med., 52: 747 (1972).

23. Milic-Emili, J., Mead, J., Turner, J. M., and Glauser, E. M.: Improved technique for estimating pleural pressure from esophageal balloons. J. Appl. Physiol., 19. 207 (1964).

24. Phelan, P.D. and Williams, H. E.: Ventilatory studies in healthy infants. Pediat. Res. 3: 425 (1969).

25. Polgar, G. and String, S. T.: The viscous resistance of the lung tissues in normal infants. J. Pediatr.. 69: 787 (1966).

26. Radford, M. Measurement of airway resistance and thoracic gas volume in infancy. Arch. Dis. Child., 49: 611 (1974).

27. Richards, C. C. and Bachman, L.: Lung and chest wall compliance of apneic paralysed infants. J. Clin. Invest., 40: 273 (1961).

28. Stocks, J.: The functional growth and development of the lung during the first year of life. Early Human Dev., I: 285 (1977)

29. Stocks, J., Levy, N., and Godfrey, S.: A new apparatus for the accurate measurement of airway resistance in infancy. J. Appl. Physiol. Respir. Environ. Exercise. Physiol., 43: 155 (1977).

30. Taussig, L. M., Harris, T. R., and Lebowitz, M. D.: Lung function in infants and young children: Functional residual capacity, tidal volume and respiratory rate. Am. Rev. Respir. Dis., 116: 233 (1977).

31. West, J. B. and Dollery, C. T.: Distribution of blood flow ventilation-perfusion ratio in the lung, measured with radioactive $\mathrm{CO}_{2}$. J. Appl. Physiol., 15: 405 (1960).

32. P. Helms was supported by the Medical Research Council (U.K.) M.G. Hulse was supported by the Institute of Child Health, Research Trust.

33. Requests for reprints should be addressed to: Dr. Peter Helms, The Respiratory Laboratory, Hospital for Sick Children, Great Ormond Street, London WC1N 3JH, United Kingdom.

34. Received for publication August 4, 1981.

35. Accepted for publication February 5, 1982.

Copyright (c) 1982 International Pediatric Research Foundation, Inc. 0031-3998/82/1611-0943\$02.00/0 